\title{
LA ORGANIZACIÓN TERRITORIAL DE ESPAÑA. UNA REFLEXIÓN SOBRE EL ESTADO DE LA CUESTIÓN Y CLAVES PARA LA REFORMA CONSTITUCIONAL
}

\author{
GREGORIO CÁMARA VILLAR
}


SUMARIO

1. INTRODUCCIÓN. 2. EL PROYECTO REPUBLICANO DE CONSTITUCIÓN FEDERAL DE 1873. 3. LA CONSTITUCIÓN DE 1931 Y LA SEGUNDA REPÚBLICA. 4. LA APERTURA DEL PROCESO AUTONÓMICO CON LA CONSTITUCIÓN DE 1978. 5. LA EVOLUCIÓN DEL ESTADO AUTONÓMICO. 6. ¿HACIA UNA REFORMA DE LA CONSTITUCIÓN? ALGUNAS CLAVES EN SENTIDO FEDERAL. 7. REFERENCIA ESPECIAL A LA CUESTIÓN CATALANA. NOTA BIBLIOGRÁFICA 


\title{
LA ORGANIZACIÓN TERRITORIAL DE ESPAÑA. UNA REFLEXIÓN SOBRE EL ESTADO DE LA CUESTIÓN Y CLAVES PARA LA REFORMA CONSTITUCIONAL
}

\author{
GREGORIO CÁMARA VILLAR ${ }^{1}$ \\ Catedrático de Derecho Constitucional \\ Universidad de Granada
}

\section{INTRODUCCIÓN}

Leibniz, como otros grandes pensadores, enunció una gran verdad: «Lo presente, producto de lo pasado, engendra a su vez lo futuro». Hago uso de la implícita metodología que este pensamiento encierra para traer a la memoria, en apretada síntesis, los elementos centrales de evolución de la organización territorial del Estado en España. Entiendo que de esta forma se puede considerar con mayor perspectiva el estado de la cuestión y establecer algunas claves para la necesaria reforma del «Estado autonómico». Es mucho, y por lo general de calidad, lo que se ha escrito sobre este tema. La pretensión de este artículo es realizar, con sustento en ese ingente trabajo, una reflexión que aspira a ser coherente y fundada sobre tan fundamental cuestión. Se trata de una mirada panorámica, un relato si se quiere, que permita ver el bosque, no un ejercicio académico al uso, preciso en el detalle. De ahí la renuncia a las notas a pié de página.

Es bien conocido que la respuesta ofrecida por el constitucionalismo histórico español ante la forma territorial del Estado ha sido, como tónica general, la de configurar a España como un Estado unitario, centralizado, simbolizado por la Monarquía, convertida en su eje salvo en cortos periodos de excepción. No en vano España, partiendo de los tiempos de los Reyes Católicos, fue precisamente modelo en el proceso de formación del Estado moderno, al que esta característica le era esencial. Ya en la

${ }^{1}$ Catedrático de Derecho Constitucional. Universidad de Granada. Departamento de Derecho Constitucional. Facultad de Derecho. Plaza de la Universidad, 1. 18071 Granada. Email: gcamara@ugr.es 
época constitucional, los esquemas centralistas plasmados por el liberalismo en la Constitución gaditana de 1812 — con obvia influencia de las premisas ideológicas sobre las que se sustentó la Revolución francesa - continuaron durante la monarquía isabelina (1834-1868), aun en la dialéctica política entre moderados y progresistas. De tal manera quedaron contemplados, por tanto, en las constituciones de 1837 y 1845, así como en la non nata de 1856. Tras la revolución septembrina de 1868, la Constitución de 1869, con independencia de los importantes cambios que traía consigo en otros terrenos, tampoco constituyó excepción a la prevaleciente concepción unitaria del Estado. Posteriormente, pasado el brevísimo paréntesis republicano —al que más adelante nos referimos- la Constitución canovista de 1876 volvió a consagrar de manera rotunda la organización unitario-centralista del Estado, sin reconocer ninguna otra instancia político-administrativa intermedia que no fueran las provincias y los municipios, con una estricta sujeción y dependencia al ejecutivo estatal, como se contemplaba en su Título X. Aunque con remisión a leyes especiales, tales esquemas se mantenían hasta para los territorios de ultramar.

Tras el desastre de 1898 con la independencia de Cuba, Puerto Rico y Filipinas, se advierte un importante despliegue de la lucha por la descentralización, especialmente en Cataluña desde los planteamientos del nacionalismo político, que ya había apuntado con fuerza en años precedentes y que condujo, en su insuficiente versión administrativa, a la vertebración de la Mancomunidad de Cataluña en 1914, continuando después la reivindicación por la autonomía regional. Aunque desde otras premisas diferentes al nacionalismo catalán, esta reivindicación también prosperaba en el País Vasco, en Galicia, y mucho más débilmente en otros territorios, como Andalucía, con algunos hitos destacados como la Asamblea de Ronda de 1918 o el Manifiesto Nacionalista de Córdoba de 1919. Sin embargo, la Dictadura del General Primo de Rivera, instaurada con el golpe de estado de Septiembre de 1923, suspendió las garantías constitucionales, reprimió estas dinámicas y dio paso a un tipo de Estado autoritario e intervencionista, anclado en un estricto y militante nacionalismo «españolista», que posteriormente, tras el quinquenio de la II República y la guerra civil, el régimen de Franco llevaría al paroxismo a lo largo de cuatro décadas.

Como contrapunto y reacción a esta pauta de prevaleciente dinámica unitario-centralista solo encontramos en nuestra historia, antes de la Constitución de 1978, dos grandes intentos de distinto signo, gestados ante la intrínseca pluralidad de nuestro país y por la creciente afirmación de las aspiraciones de autogobierno de algunos territorios, fundamentalmente Cataluña. Estos dos intentos coinciden, significativamente, con las dos Repúblicas. La primera (1873-1874) pretendió afrontar la cuestión territorial mediante el proyecto de establecimiento de un Estado de cuño federal, mientras que la segunda (1931-1936) ensayó la compatibilidad de un llamado «Estado integral» con la autonomía de las regiones.

Pero ni una ni otra tentativa de solución tuvo la fortuna política ni el tiempo necesario para poder mostrar su eventual virtualidad y eficacia. La primera experiencia se gestó y consumió en no más de unos meses, dentro del ojo del huracán de una 
situación extraordinariamente convulsa, desembocando en la anarquía del cantonalismo y sin llegar a tener vigencia alguna. La segunda, llevada muy parcialmente a la práctica a lo largo de un quinquenio de grandes tensiones sociales y políticas en medio de una intensa crisis económica, fue bruscamente interrumpida por la sublevación militar encabezada por el General Franco, que produjo una cruenta guerra civil de tres años y, a su fin, la inmediata implantación del régimen dictatorial que llevó hasta sus últimas consecuencias un modelo de organización férreamente totalitaria del Estado, evolucionando después a diferentes estadios de una situación autoritaria — con la misma razón de ser- mediante el permanente control y represión de la población y de los elementos identitarios de determinados territorios desde todos los ámbitos del aparato del Estado.

Aunque no sea pertinente ni posible ahora entrar en el detalle de estos hitos de nuestro pasado, conviene realizar unas referencias generales para seguir el hilo político-constitucional que condujo al producto presente de esta nuestra historia, el actual Estado autonómico, y apreciar su evolución y lo que ha generado desde el «proceso autonómico» que se abrió con la Constitución de 1978. De tal manera estaremos en situación de poder calibrar con más perspectiva las tensiones que hoy se agitan en su interior y proponer fundadamente los elementos de reforma a nuestro juicio necesarios para afrontar la cuestión territorial con alguna expectativa de éxito (al menos para otro largo periodo histórico).

Intentaremos mostrar primero que si bien en 1873, 1931 y 1978 hubo un rotundo rechazo del centralismo y una aspiración indubitada al establecimiento de la autonomía regional bajo distintas formas, no pudo fraguarse en ninguno de estos momentos, por diferentes razones, una neta voluntad constituyente en esta materia que estuviera en condiciones de sostener eficazmente un modelo definido. Por eso la cuestión territorial sigue estando recurrentemente abierta en canal, a la espera de una constitucionalización adecuada que permita vertebrar con la estabilidad necesaria nuestro Estado. Después, tras un diagnóstico general del modelo autonómico en su evolución en la órbita del federalismo, abordaremos los elementos centrales para una reforma en clave federal.

\section{EL PROYECTO REPUBLICANO DE CONSTITUCIÓN FEDERAL}

\section{DE 1873}

A comienzos del último tercio del Siglo XIX, en un ambiente muy crispado de extraordinaria conflictividad social y política, con el fracaso de la monarquía y tras la renuncia de Amadeo I de Saboya a la corona, se celebraron elecciones a Cortes Constituyentes que proclamaron la República democrática federal en Febrero de 1873. El Proyecto de Constitución Republicano Federal redactado por Emilio Castelar y presentado en el mes de Julio de aquel año — que ni llegó a entrar en vigor ni fue siquiera discutido, al menos en su integridad - supuso el primer y embrionario intento de 
buscar solución a la organización territorial de nuestro Estado desde una perspectiva pluralista. Se inspiró muy de cerca en la Constitución de los Estados Unidos de 1787 tanto en la terminología como en los principios inspiradores, en la división de poderes, los aspectos orgánicos y el reparto de competencias entre la federación y los estados miembros. De su examen se desprende, pese a sus peculiaridades, como ha destacado Roberto Blanco Valdés, su carácter «netamente federal, perfectamente comparable a los de esa naturaleza que existían entonces en el mundo: los de Estados Unidos, Suiza, Canadá, y con los necesarios matices, Alemania». A juicio de otros autores, sin embargo, no llegaba a ser tan marcadamente federal, toda vez que —al decir de Antonio Torres del Moral - adoptaba criterios que el Derecho y la doctrina posteriores han calificado como de autonomía regional. En cualquier caso, con los matices propios de nuestra particular idiosincrasia, mediante este Proyecto, sin duda atrevido y avanzado para la situación política que se vivía en aquella época, se pretendía claramente una construcción federal de arriba-abajo que, como se expresaba en el Dictamen de la Comisión Constitucional que lo elaboró, permitiera establecer una sólida federación, con raíces en nuestra historia, sin perjuicio de la unidad nacional. Se partió así del hecho de la unidad de España y para la concreción de los estados miembros en su artículo 1 se combinó el criterio de tomar en consideración una genérica y adaptada prefiguración de los antiguos reinos españoles más la división provincial entonces existente.

En este Proyecto la Nación, España, era una, organizada mediante la forma de gobierno republicana, residenciando la soberanía en todos los ciudadanos. Respecto a la organización territorial adoptaba una visión inspirada — aunque sin formularlo expresamente- en el principio de subsidiariedad, si bien con una concepción un tanto imprecisa y autorreferencial (art. 40). En este esquema de tres niveles de gobierno, el intermedio, entre el municipio y la federación o Nación, se configuraba como un «estado regional», predicando de cada uno de ellos una especie de soberanía limitada y subordinada, en realidad autonomía (art. 43, último párrafo), según la cual estos entes tendrían «completa autonomía económico-administrativa y toda la autonomía política compatible con la existencia de la Nación» (art. 92).

Según esta caracterización, los estados regionales podían darse a sí mismos una constitución política que no podría contradecir en ningún caso el marco dispuesto en la Constitución federal (art. 93), que debería ser examinada y sancionada por las Cortes federales en orden a comprobar «si están respetados o no en ellas los derechos de la personalidad humana, los límites de cada Poder y los preceptos de la Constitución federal» (art. 102). En particular, se establecía que los estados no podrían legislar «ni contra los derechos individuales, ni contra la forma republicana, ni contra la unidad y la integridad de la Patria, ni contra la Constitución federal» (art. 99). Respecto al orden organizativo interno de los estados miembros, el Proyecto preveía una completa autonomía para la formación de sus respectivos gobiernos y sus asambleas legislativas por sufragio universal (arts. 94 y 95. De otro lado, se prohibía la gestación de un nuevo estado en el seno de otro (art. 104), así como la de otro estado a partir de la 
unión de dos o más de ellos, salvo que mediare el consentimiento de las respectivas Cortes de los estados interesados y la sanción de las Cortes federales (art. 105). Expresamente se disponía la igualdad de derechos de todos los ciudadanos en cualquiera de los estados (art. 103).

Conforme al carácter federal del sistema diseñado por este Proyecto, las Cortes se componían de dos Cámaras, Congreso y Senado. El Senado, inspirado en el modelo norteamericano, representaría a los territorios en número de cuatro senadores por estado, con independencia de su población, que serían elegidos por sus respectivas Cortes (art. 52). Respecto a la distribución de competencias se atribuía en el Título $\mathrm{V}$ un conjunto de ellas a la Federación, el considerado esencial en la concepción de aquella época: relaciones exteriores, declaración de guerra, conservación de la unidad y la integridad nacional, fuerzas armadas, correos y telégrafos, ferrocarriles, deuda, códigos generales, moneda, pesos y medidas, aduanas y aranceles..., entendiendo que las demás competencias y facultades serían, respetando ese marco, propias de los estados que la integran. Siempre, naturalmente, con la obligación de observar los límites establecidos para los poderes estatales. En el Título XIII se contemplaban, a su vez, determinadas especificaciones de la autonomía de los estados.

Se trataba, pues, de un esquema federal bastante racionalizado y con cierta simplicidad a partir del modelo norteamericano, abierto por ello a interesantes posibilidades de desarrollo y evolución. Pero la convulsa situación política del país —embarcado en conflictos bélicos ante la sublevación cubana y la tercera guerra carlista- en la que, además, jugaría un papel fundamental y determinante el profundo enfrentamiento entre los federalistas radicales e intransigentes y los pactistas, arruinó por completo este proyecto. Justo cuando se presentó en Julio de 1873, la República ya estaba atenazada por graves episodios de la guerra carlista en Cataluña y por la huelga de la industria papelera que dio lugar a amotinamientos y asesinatos, y se produjo también la rebelión cantonalista generada por el faccionalismo intransigente que rápidamente se extendió por una buena parte de España tras la sublevación de Cartagena. Tales episodios hacían presagiar que la Primera República caminaba irremediablemente hacia su inmediato final. En la sesión parlamentaria celebrada el día anterior al golpe de Estado de Pavía del 3 de Enero de 1874, Castelar, dirigiéndose a los radicales, preguntó: « ¿Y el Proyecto?». Y él mismo respondió: «Lo quemasteis en Cartagena».

No hubo debate constituyente propiamente tal para este Proyecto - aunque fuera parcialmente debatido en plena rebelión cantonal- y por eso no resulta posible conocer cuales hubieran podido ser los cambios resultantes de la eventual culminación de ese proceso ni cómo hubiera podido producirse su evolución y consolidación en el caso de haber prosperado, en cualquiera hubiese podido ser la forma, en un contexto diferente de menor fragmentación y radicalización política. El Proyecto fue rechazado por los conservadores, por los radicales y por el grupo federal más exacerbado (que apoyó la rebelión cantonal), en tanto que fue débilmente sostenido por los republicanos más centristas y moderados. Lo que había ocurrido en este caso, en definitiva, es 
que no pudo fraguarse una auténtica voluntad constituyente porque, de un lado, la derecha política no se sentía concernida por este modelo y, de otro, existieron grandes y muy profundas divisiones entre las diferentes fracciones del republicanismo federal.

\section{LA CONSTITUCIÓN DE 1931 Y LA SEGUNDA REPÚBLICA}

La Segunda República, proclamada el 14 de Abril de 1931, protagonizó un segundo intento de solución de la cuestión territorial, poco más de un año después de la caída de la Dictadura de Primo de Rivera. Heredó una situación muy conflictiva, toda vez que en aquel tiempo ya se había producido una peligrosa acumulación y radicalización de los problemas no resueltos que arrastraba la sociedad española, a los que había que sumar aquellos otros que se habían generado en el cambio de siglo por las nuevas tensiones nacionales e internacionales. Entre ellos se encontraba la cuestión territorial, a la que las fuerzas políticas republicanas se hubieron de enfrentar como cuestión de principio en el Pacto de San Sebastián, celebrado el 17 de Agosto de 1930, poco antes de que la República naciera. En él se acordó sin detalle alguno la presentación por Cataluña a las futuras Cortes Constituyentes de un estatuto, libremente y en su día, para regular su autogobierno; acuerdo que se hizo extensivo a todas aquellas otras regiones con personalidad definida que sentían la necesidad de una vida política autónoma.

Constituido el Gobierno Provisional, se creó una Comisión Jurídica Asesora encargada de redactar un Proyecto de Constitución. Celebradas las elecciones a Cortes, la citada Comisión remitió al Ministro de Justicia, a la sazón el socialista Fernando de los Ríos, un anteproyecto que no se decantaba ni por el federalismo ni por una mera descentralización administrativa, sino que optaba por una nueva vía, todavía innominada, conformada por un Estado unitario pero compatible con la existencia de regiones políticamente autónomas. La Comisión constitucional lo tomó como punto de partida, huyendo tanto del inútil y férreo unitarismo de nuestra historia, como del fracasado federalismo de inspiración pimargalliana que con tan poca fortuna intentó canalizarse mediante el Proyecto de 1873. Inspirándose en las posiciones doctrinales de Hugo Preuss, la Comisión se orientó por el «Estado integral», recogiendo el principio del Estado unitario, pero respetuoso de las autonomías territoriales, pretendiendo así la ansiada vertebración de la unidad de la nación española con la diversidad territorial. En este camino se cruzó el simultáneo debate del Estatuto de Nuria, de orientación federal, condicionando el desarrollo del propiamente constitucional (situación que se produjo tras los episodios de la proclamación por Maciá del «Estat catalá», en el marco de una Federación de Repúblicas Ibéricas, el mismo 14 de Abril de 1931, inmediatamente retirada tras negociar con el Gobierno).

El artículo primero de la Constitución de 1931 proclamó que «la República constituye un Estado integral, compatible con la autonomía de los Municipios y las Regiones». Con independencia de los avatares tan conflictivos que en esta materia se 
produjeron a lo largo del quinquenio, en los que no podemos entrar, baste constatar a nuestros propósitos que la Segunda República asumió el principio de la autonomía regional partiendo del reconocimiento de las viejas aspiraciones autonomistas de diversas regiones españolas, estableciendo en el artículo 11 la facultad de organizarse en regiones autónomas a todas aquellas que, dadas ciertas características históricas, culturales y económicas comunes, así lo acordasen, presentando el correspondiente Estatuto conforme al procedimiento establecido por el artículo 12, que una vez aprobado por las Cortes sería la ley básica de la organización político-administrativa de la región autónoma. Por otra parte, en los artículos siguientes se contemplaban los listados de competencias exclusivas, legislativas y ejecutivas, del Estado, las ejecutivas de las regiones autónomas (y, en su caso, legislativas, en la medida de su capacidad política) y las que pudiesen asumir con carácter exclusivo tanto en las funciones legislativa como de ejecución. Se prohibía la federación de las regiones autónomas (art. 13) y, por otra parte, se disponía la necesaria igualdad de trato de todos los españoles con independencia de la región en que se hallasen (art. 17). De acuerdo con la lógica de los Estados regionales del periodo de entreguerras, que reconocían autonomía a determinadas regiones con minorías étnicas o culturales, no establecía un Parlamento bicameral cuya segunda cámara estuviera destinada a integrar la voluntad territorial en la nacional.

Cataluña fue la primera región que presentó un proyecto de estatuto que, tras prolongados debates, fue promulgado por ley de 15 de Septiembre de 1932. El Estatuto de Nuria, que establecía la Generalitat como órgano de gobierno de la región, tanto en su interpretación como en su vigencia estuvo muy condicionado por las luchas de partido durante el quinquenio republicano, hasta el punto de que el autogobierno solo tuvo propiamente efectividad durante algo más de dos años, pues fue suspendido como consecuencia de la rebelión de la Generalitat en octubre de 1934 y la proclamación de la República Catalana —al frente de la cual estaba el Presidente Lluis Companys - y solo tras el triunfo del Frente Popular en Febrero de 1936 recobraría de nuevo vigencia. El País Vasco fue la segunda región española que accedió a la autonomía, si bien lo hizo en fecha ya muy tardía, julio de 1936, como consecuencia no solo de los problemas de política nacional como era la enconada oposición de las derechas, sino también de las tensiones internas que se vivían entre los propios partidos y territorios vascos. Siguiendo un complicado proceso, Galicia plebiscitó el Estatuto el 5 de Junio de 1936. Andalucía, Asturias, León y Castilla, País Valenciano, Aragón, Baleares y Canarias elaboraron anteproyectos o proyectos de autonomía, viniendo la sublevación militar y la guerra civil a acabar con tales procesos.

La Segunda República, en definitiva, pretendió afrontar el problema secular del regionalismo español intentando sentar las bases para dejarlo encauzado en un marco abierto de descentralización política de cuño unitario-regional, no federal. Es difícil emitir un juicio acerca de si las soluciones propuestas fueron o no acertadas, teniendo en cuenta que solo dos regiones alcanzaron efectivamente la autonomía, y una de ellas en fecha ya muy tardía, antes de que la experiencia republicana fuera cortada de raíz 
por la sublevación militar y la guerra civil. Pero sí podemos constatar que tampoco hubo en este momento histórico una definición precisa de un modelo de organización territorial. El Estado integral quedaba prefigurado constitucionalmente como un proceso muy abierto de Estado «descentralizable», trasluciendo, más allá del rechazo al característico unitarismo de nuestra historia, la ausencia en esta materia de una voluntad constituyente neta y definida. En cualquier caso, esta experiencia inspiraría de modo muy cercano el nuevo intento de solución que, con notable éxito prolongado a lo largo de décadas, alentaría la Constitución de 1978 y que en estos tiempos vive grandes tensiones y rechazos, sobre todo provenientes de un nacionalismo radical, ya abiertamente mutado en independentista en Cataluña.

\section{LA APERTURA DEL PROCESO AUTONÓMICO CON LA CONSTITUCIÓN DE 1978}

Acabado el franquismo tras cuatro décadas desde el final de la Guerra Civil, durante la etapa de la transición de la dictadura a la democracia (1976-1978) se adoptaron las decisiones fundamentales sobre las formas de Estado y de gobierno que posteriormente se consagrarían en el texto constitucional de 1978. Estas decisiones conformaban en sustancia los tres grandes pilares sobre los que se edificó el consenso constitucional: el Estado democrático y social, la monarquía parlamentaria y un inacabado modelo de organización territorial basado en el reconocimiento del derecho a la autonomía de nacionalidades y regiones.

Por entonces ya existía previamente una clara orientación política hacia un modelo de reconocimiento generalizado de la autonomía política. Las principales formaciones políticas y amplios sectores de la opinión pública en buena medida identificaban autonomía con democracia (recuérdese el tan coreado lema «Libertad, Amnistía, Estatuto de Autonomía»). Existía, además, un extendido sentimiento acerca de que la descentralización política era una forma de organización territorial no solo necesaria para nuestro país sino también mucho más eficaz que la centralización, por lo que se estimaba que debería abrirse la posibilidad de su generalización, si bien se discrepaba respecto a la intensidad relativa que ésta debería tener en cada territorio. De esta manera se adoptaron una serie de medidas en esta dirección, como el restablecimiento provisional de la Generalitat de Cataluña (Real Decreto-Ley de 29 de septiembre de 1977) y el nombramiento como su presidente de Josep Tarradellas, presidente de la Generalitat catalana en el exilio. Inmediatamente después se aprobó el régimen preautonómico para el País Vasco y se produjo su extensión a todas las regiones españolas mediante los correspondientes Reales Decretos-Leyes. Este régimen de preautonomías, sin duda, jugó un importantísimo papel para el asentamiento paulatino del principio autonómico incluso antes de que se aprobara la Constitución.

Pero la descentralización política que se pretendía desde la transición respondía también al objetivo fundamental de integrar definitivamente en el Estado — resol- 
viendo así el intenso y costoso pleito histórico al que venimos haciendo referenciaa las Comunidades que habían desarrollado a lo largo de los siglos XIX y xx un fuerte sentimiento autonomista anclado en un sentido diferenciado de su identidad respecto de la del conjunto del Estado (Cataluña y el País Vasco). Es decir, se trataba de dar respuesta a los problemas que se planteaban en España por los nacionalismos políticos en estas comunidades, una verdadera, permanente y decisiva «asimetría política» de nuestro país (Roberto Blanco). Ahora bien, si el rechazo al centralismo era prácticamente unánime en el aquél momento, no existía el mismo grado de unanimidad respecto al modelo que habría de venir a sustituirlo, porque mientras que para algunos la solución estaba en el modelo federal (las fuerzas de la izquierda, según diferentes intensidades), otros abogaban por el regionalismo y otros, aun, por la puesta en marcha de medidas de simple descentralización administrativa (las fuerzas políticas del centro y de la derecha, respectivamente).

La pretendida solución alcanzada mediante el pacto constituyente consistió en una combinación o compromiso entre las principales fuerzas políticas a favor de la apertura hacia la descentralización, pues partiendo de la indisoluble unidad de la nación española, se reconoce y garantiza al mismo tiempo el derecho de los territorios a constituirse en Comunidades Autónomas con facultades de autogobierno, esto es, se consagró el principio dispositivo para acceder a la autonomía, configurarla y desarrollarla. En definitiva, de entre las distintas opciones posibles de organización territorial del poder, se eligió de nuevo un Estado «descentralizable» sin presuponer su resultado final (aunque se pretendiera políticamente encauzado en su trabazón interna en dos diferenciados niveles de autonomía). Y se hizo siguiendo en buena medida el precedente del tertium genus de la Constitución de 1931, ofreciendo también en principio notorias analogías con el modelo de Estado regional italiano, inspirado a su vez en nuestra Constitución republicana.

Debe destacarse, pues, que no existe en la Constitución de 1978 una opción expresa por un determinado «modelo» de Estado en el plano de la organización territorial del poder, sino el establecimiento de un conjunto normativo muy abierto, fundado en el reconocimiento del derecho a la autonomía de las nacionalidades y regiones, para que el proceso descentralizador pudiera iniciarse mediante su ejercicio, pero permitiendo diversas combinaciones y grados posibles de descentralización administrativa y política. Una situación muy peculiar que tempranamente caracterizara P. Cruz Villalón como de «desconstitucionalización de la estructura territorial del Estado». Esta opción se ha perfilado después como «modelo» sui generis con el nombre de «Estado autonómico», aportado por la doctrina académica, conforme se ha venido desarrollando de manera abierta, compleja y un tanto desordenada, incluidas improvisaciones, mediante determinadas decisiones normativas, la práctica política y la interpretación constitucional. Es verdad que como dijera Sánchez Agesta, la denominación «Estado autonómico» que acabó imponiéndose responde bien a la realidad que describe, pues se trata de «un Estado nacional que reconoce el derecho a la autonomía de las nacionalidades y regiones sobre las que se ha constituido en la 
historia». Pero no es menos expresivo de nuestro discurrir histórico que ni en 1931 ni en 1978 — como hemos expuesto- se haya podido definir y concretar un modelo acabado de constitución territorial en la propia norma constitucional como punto de partida. Esto trasluce de nuevo, como ha destacado Javier Pérez Royo, la ausencia de una específica voluntad constituyente de la sociedad española respecto de la estructura del Estado, que ciertamente sabía lo que no quería (la centralización, el estado unitario) pero, por distintas razones, no lo que quería como modelo concreto de descentralización, dejando así muy abierta la puerta a su desarrollo y evolución mediante el ejercicio del derecho a la autonomía.

El marco jurídico constitucionalizado de esta opción responde a estos perfiles fundamentales: la soberanía pertenece a un único titular, el pueblo español como totalidad, «del que emanan todos los poderes del Estado» (art. 1.2), fundamentándose la Constitución en «la indisoluble unidad de la Nación española, patria común e indivisible de todos los españoles», reconociendo y garantizando «el derecho a la autonomía de las nacionalidades y regiones que la integran y la solidaridad entre todas ellas» (art. 2), sin que se identifique nominalmente cuales sean unas y otras ni se especifiquen efectos jurídico-políticos diferenciados para ambas denominaciones, por lo que del ejercicio de este derecho surgirían entidades con una denominación común: «Comunidades Autónomas» (art. 137). Así pues, la nación es una e indivisible y el Estado, fundamentado en los principios de unidad y autonomía, es complejo y diverso, esto es, organizado territorialmente según resulte del ejercicio del derecho a la autonomía por parte de los territorios que lo integran. Por su parte, el Título VIII comienza con una norma que establece que «el Estado se organiza territorialmente en...las Comunidades Autónomas que se constituyan» (art. 137) y establece los procedimientos de acceso a la autonomía y otras decisiones fundamentales (aunque incompletas) para hacer operativa la organización territorial resultante. Cabe destacar básicamente los dos grandes procedimientos de acceso configurados en los artículos 143 (ordinario y de vía lenta en la asunción de plenitud de competencias, que solo transcurridos cinco años podría aumentarlas mediante la correspondiente reforma) y 151 (especialmente agravado y de vía rápida en el acceso a la plenitud competencial permitida por el art. 149, para el cual, además, se disponía específicamente un conjunto institucional propio de un sistema parlamentario de gobierno para las Comunidades que a través del mismo se constituyeran, no previsto expresamente para las de vía ordinaria). De otro lado, la Disposición Transitoria Segunda establecía grandes ventajas procedimentales de acceso directo a la autonomía plena a los territorios que en el pasado hubiesen plebiscitado afirmativamente proyectos de Estatuto de autonomía. Otra pieza importante en este esquema eran las leyes del artículo 150, especialmente las configuradas en su apartado segundo, orgánicas de transferencia o delegación de competencias del Estado a las Comunidades Autónomas en materias de su titularidad que, "por su naturaleza», sean susceptibles de transferencia o delegación, abriendo así una potencial e imprecisa vía extraestatutaria permanente de incorporación de nuevas competencias. El artículo 145.1 prohibía la federación de 
Comunidades Autónomas y el 155 un mecanismo de coerción estatal frente al incumplimiento de obligaciones constitucionales o legales por parte de aquellas o por la realización de actuaciones que atentaren gravemente contra el interés general de España.

En definitiva, lo que la Constitución prefiguró fue propiamente la apertura de un «proceso autonómico», por lo que la definición, plasmación, desarrollo y relativa estabilización de un modelo más concreto ha requerido de mucho tiempo, y aun así todavía continúa abierto, aunque se hayan agotado prácticamente sus posibilidades de más desarrollo, sobre todo tras la reforma del Estatuto de Autonomía de Cataluña en 2006, la oleada de reformas de los llamados estatutos de segunda generación y la doctrina del Tribunal Constitucional establecida fundamentalmente en la Sentencia 31/2010 sobre el Estatut.

Según lo dispuesto en el art. 2 CE y en el Título VIII, recapitulando, quedaba territorialmente prefigurado un Estado con contornos muy imprecisos, necesariamente abiertos por la consagración del principio dispositivo de acceso a la autonomía y por la tácita delegación en el legislador orgánico de la competencia para cerrar los múltiples enunciados de apertura en él presentes. Pero a partir de ese entramado normativo superior, el legislador estatal y las propias nacionalidades y regiones una vez constituidas, así como la riqueza de las experiencias, han configurado y concretado después, en su entrelazamiento con los respectivos Estatutos de Autonomía (bloque de la constitucionalidad), los perfiles característicos de un avanzado Estado autonómico, viniendo la jurisprudencia del Tribunal Constitucional a precisar y consagrar casuísticamente los pilares doctrinales sobre los que se asienta la llamada «constitución territorial». En este dilatado y complejo proceso son muchos los conceptos y las soluciones que precisamente se han tomado de las experiencias federales comparadas. El sistema se ha caracterizado así por una gran flexibilidad, construyéndose de modo gradual, y pudiera decirse que un tanto «funcionalista», llegando a ser y a funcionar en sus estadios más recientes como un sistema federal en los hechos. Hay que decir que de manera sin duda bastante aceptable y exitosa hasta comienzos de la pasada década, pues a él se deben en buena parte muchos de los logros alcanzados en el desarrollo político, económico, social y cultural que ha experimentado España desde la culminación de la Transición hasta nuestros días. Conviene ahora detenernos en una panorámica mirada a su evolución.

\section{LA EVOLUCIÓN DEL ESTADO AUTONÓMICO}

En una etapa inicial (1979-1983), los problemas fueron los propios de la implantación de la autonomía. Las primeras Comunidades que surgieron fueron el País Vasco y Cataluña (18 de diciembre de 1979) y Galicia (6 de abril de 1981), cuyo acceso se realizó conforme a lo previsto en el artículo 151.2 y la Disposición Transitoria segunda de la Constitución, en tanto que fueron estos territorios los únicos que 
llegaron a plebiscitar estatutos de autonomía durante la Segunda República. Andalucía, tras mostrar una decidida e inequívoca voluntad autonomista — puesta fundamentalmente de relieve en la gran manifestación del 4 de diciembre de 1977- fue la única Comunidad que accedió a la autonomía siguiendo la ardua tramitación del procedimiento establecido en el artículo 151 de la Constitución y en contra de la posición mantenida por el Gobierno y la entonces gobernante formación política Unión de Centro Democrático, que se empeñaron a fondo en poner todos los obstáculos y trabas posibles en el camino hacia ese objetivo. Andalucía, que no podía disfrutar de la muy discutible ventaja procedimental establecida por la Disposición transitoria segunda - en tanto que su estatuto no se pudo plebiscitar durante la República al producirse la sublevación militar y la guerra civil- eligió desde el principio esta vía y logró, tras un accidentado proceso, elaborar y aprobar su Estatuto en diciembre de 1981 con las instituciones políticas del artículo 152 y el mayor techo competencial permitido por el artículo 149, equiparándose así a las llamadas «nacionalidades históricas» con una autonomía plena y de vía rápida.

De esta manera este proceso facilitó objetivamente que las Comunidades que a partir de entonces se constituyeran por la vía del 143 también tuviesen instituciones políticas equiparables. Habida cuenta de que en ciertos sectores, incluido el Gobierno, se pretendía circunscribir fundamentalmente a Cataluña y al País Vasco el modelo de autonomía plena o más intensa y rápida (Galicia era más bien una consecuencia del criterio formalmente adoptado para ello), Andalucía incidió con fuerza en el conjunto del proceso autonómico, rompiendo esta posible dinámica y propiciando que se abandonase la idea de que existieran permanentemente dos tipos diferenciados de Comunidades Autónomas, circunscribiéndose las diferencias a los «hechos diferenciales» constitucionalmente reconocidos y a los ámbitos competenciales de cada Comunidad asumidos en virtud del principio dispositivo $-\mathrm{o}$, excepcionalmente, recibidos por vía extraestatutaria - y lo que fuera produciendo y consolidando el mismo ejercicio de esas competencias. Así, el papel que desempeñó el proceso autonómico andaluz en el diseño final del Estado de las Autonomías fue el de introducir la dinámica de una distribución del poder político tendencialmente homogénea, sin situaciones diferenciadas que pudieran considerarse de privilegio para algunas regiones, pero con pleno respeto de las singularidades territoriales. Sin Andalucía y su posición en aquél momento inaugural no se podría entender, por tanto, el decurso posterior del Estado autonómico.

Hechos destacables de este periodo fueron también, de un lado, la adopción de las medidas necesarias para la financiación de la autonomía mediante la Ley Orgánica 8/1980, de Financiación de las Comunidades Autónomas. De otro, tras el fallido golpe de Estado de 23 de febrero de 1981, se trató también de poner orden en el desarrollo del proceso autonómico a través de los Acuerdos Autonómicos de 31 de julio de 1981. La consecuencia de los mismos fue que los demás territorios accederían a la autonomía por la vía del art. 143 (por tanto, con menor techo competencial), aunque en todo caso se trataría también de autonomía política con las institu- 
ciones del 152. La excepción fue Navarra que accedió a la autonomía plena mediante lo previsto en la Disposición adicional primera (Ley Orgánica 13/1982, de 10 de agosto, de reintegración y amejoramiento del Régimen Foral de Navarra - LORAFNA - ). Valencia y Canarias, aunque accedieron por la vía del 143, recibirían, sin embargo, otras competencias complementarias mediante las correspondientes leyes orgánicas de transferencias, en virtud de lo previsto en el artículo 150.2 (Ley Orgánica 12/1982, de 10 de agosto, de transferencia a la Comunidad Valenciana -LOTRAVA - y Ley Orgánica 11/1982, de 10 de agosto, de transferencia a Canarias - LOTRACA — , respectivamente). De esta manera se generalizaba la autonomía como autonomía política, si bien con un distinto nivel competencial. Por otra parte, el intento de «racionalización» que se plasmó en la Ley Orgánica de Armonización del Proceso Autonómico de 30 de Julio de 1982 (LOAPA), no llegaría a materializarse. Este intento resultaría fallido, tras ser recurrida la ley ante el TC por la vía - entonces existente, luego derogada y recientemente recuperada para los Estatutos de Autonomía- del recurso previo de inconstitucionalidad contra Leyes Orgánicas. La STC 76/1983, declaró su inconstitucionalidad en sus elementos centrales (sus pretendidos caracteres orgánico y armonizador), determinando la imposibilidad de «cerrar» la «apertura autonómica» del Título VIII CE mediante «leyes interpretativas». Pese a ello, lo que quedó de la LOAPA tras la declaración de inconstitucionalidad conformó la Ley del Proceso Autonómico (LPA, Ley 12/1983, de 14 de octubre), en la que se contuvieron muy importantes preceptos para la articulación de la asunción de competencias. Por consiguiente, en 1983 finaliza esta fase con todos los Estatutos aprobados y todo el territorio nacional, con la excepción de Ceuta y Melilla, organizado en 17 Comunidades Autónomas.

La segunda etapa (1983-1992) consistiría sustancialmente en el inicio y desarrollo de la dinámica propia de las transferencias y de funcionamiento del conjunto del sistema con medidas sobre financiación; la previsible y necesaria interacción que tendría que generar el esquema de compartición competencial bases/desarrollo, con sus problemas aparejados, entre ellos las frecuentes invasiones competenciales estatales por apurar la regulación básica, constriñendo la competencia autonómica de desarrollo, o el recurso cada vez mayor a títulos transversales; también la puesta en pie y desarrollo de una línea política de colaboración y cooperación, fundamentalmente entre el Estado y las Comunidades Autónomas. Es importante recordar que los Acuerdos Autonómicos de 28 de febrero de 1992, entre Gobierno, PSOE y PP, estuvieron dirigidos a incrementar el techo competencial de las CCAA del artículo 143 CE, acuerdos que se materializaron en la Ley Orgánica 9/1992, de 23 de diciembre, realizándose la transferencia generalizada de competencias mientras se procedía a la reforma de los Estatutos. En línea con la dinámica homogeneizadora del periodo, se produjo así una igualación sustancial en las competencias de las Comunidades de segundo grado o de vía lenta con las del primero, que culminaría con las posteriores reformas estatutarias aprobadas entre 1996 y 1999. Al mismo tiempo se reimpulsaba el proceso de traspasos con carácter general, y comenzaron a institucionalizarse y 
regularse los mecanismos de colaboración y cooperación entre el Estado y las CCAA que se habían venido generando con cierta espontaneidad, las más de las veces, en la práctica política.

La tercera etapa (1993-2006) cabe caracterizarla por las reformas estatutarias antes referidas y por el hecho de que se completara el mapa autonómico mediante los Estatutos de autonomía de las Ciudades Autónomas de Ceuta y Melilla (Leyes Orgánicas 1 y 2 de 1995, de 13 de marzo). La autonomía, pues, se extendió ya a todo el territorio del Estado en una dimensión consolidada. Cabe además subrayar el hecho de que se regulara, mediante Resoluciones de la Presidencia del Congreso de los Diputados de 16 de marzo de 1993 y de la Presidencia del Senado de 30 de septiembre de 1993, el procedimiento que habían de seguir los proyectos de reforma de los Estatutos elaborados por los parlamentos autonómicos (que ostentan el monopolio de la iniciativa de reforma). Estas resoluciones reconocen a dichos parlamentos la facultad de retirar la iniciativa de reforma antes de la aprobación del texto definitivo por las Cortes Generales, haciéndolos así inmodificables por las Cortes si no media el consentimiento de los respectivos parlamentos autonómicos. También es en esta etapa cuando surgieron los centrales problemas de ajuste del Estado autonómico, a lo que no es ajeno precisamente el hecho de que estos tiempos coincidieran con la finalización de las legislaturas de mayoría absoluta y el consiguiente necesario recurso a la adopción de acuerdos con minorías nacionalistas para poder gobernar. Se empieza así a debatir con intensidad sobre la reforma del Senado (pensando en la subsanación del déficit de representación territorial y de cooperación intergubernamental e integración de la diversidad en una instancia central común del Estado con la presencia de las Comunidades Autónomas); del mismo modo, comienza a preocupar intensamente el más que evidente desajuste entre la descentralización del gasto y la centralización de los ingresos, por lo que se centra la atención en la búsqueda de mecanismos que permitan la corresponsabilidad fiscal; la autonomía local, la acción exterior de las CCAA y su participación en el proceso de la construcción europea, los hechos diferenciales, la compatibilidad entre bilateralidad y multilateralidad, entre otros aspectos, constituyen también otros temas importantes en el debate político y jurídico de esta etapa.

En definitiva, a estas alturas, en ejercicio del derecho a la autonomía y en desarrollo de las previsiones constitucionales, a lo largo de estas etapas se fue construyendo un modelo de Estado autonómico que crecientemente ha incrementado, tendiendo a la igualación, los niveles de autogobierno de las Comunidades Autónomas, hasta el punto de que hemos asistido en los hechos a la puesta en pie de un modelo de Estado con niveles de autogobierno equiparables o, en algunos casos, superiores, a los que disfrutan algunos Estados miembros de Estados federales, tanto en nuestro entorno como en otras latitudes. En este sentido, pues, nuestro Estado es como si fuera federal y no puede decirse, por tanto, que el Estado autonómico haya defraudado las aspiraciones autonomistas de las diferentes regiones y nacionalidades, dejando a salvo, lógicamente, las manifiestas quejas políticas de las fuerzas nacionalistas para mante- 
ner el proceso indefinidamente abierto, como está en su naturaleza ideológica y política, para diferenciarse de otras regiones consideradas del «común de la estirpe», por utilizar una gráfica expresión del maestro García de Enterría; y también, en determinadas coyunturas, para estar en situación de ventaja de cara a obtener contrapartidas políticas, especialmente en aquellos casos en que ha sido necesario contar con fuerzas nacionalistas para disponer de la mayoría parlamentaria necesaria para gobernar en el Estado.

Una cuarta etapa vendría caracterizada por los más recientes procesos de reforma estatutaria y la entrada en crisis del sistema (2006 en adelante). Aunque los niveles de autogobierno de las CCAA sean muy elevados y el rendimiento global del Estado autonómico haya de ser positivamente valorado, éste ha venido mostrando importantes disfunciones, que tienen que ver, fundamentalmente, con los siguientes aspectos: la escasa claridad y la consiguiente apertura del sistema de distribución de competencias, lo cual ha provocado también un gran defecto congénito del Estado autonómico, cual es la notoria escasez de «calidad» de la autonomía en determinados aspectos, debida al sostenido abuso del Estado en el establecimiento y regulación de las bases y el recurso a títulos horizontales para regular determinadas materias, recortando y condicionando la capacidad autonómica para la definición, establecimiento y desarrollo de su propio espacio político en las materias de su competencia; la relativa indefinición de un modelo de financiación autonómica estable, suficiente y aceptado por todos; la ausencia de una instancia de participación adecuada y eficaz de las Comunidades Autónomas en la definición de la voluntad estatal (que el actual Senado no cumple ni puede cumplir), como expresión central de gobierno compartido en un Estado compuesto; la falta de arraigo y caracterización jurídico-política del principio de lealtad; las carencias de una deficiente articulación y funcionamiento de los mecanismos de colaboración y cooperación del Estado con las Comunidades Autónomas e incluso de los de estas entre sí, como tónica general; y la generalizada y disgregadora prevalencia de las relaciones bilaterales sobre las multilaterales. Todo ello ha venido generando una alta conflictividad, traducida en los correspondientes recursos ante el Tribunal Constitucional.

Tales aspectos centrales, junto con el mantenimiento de la apertura del sistema en función del principio dispositivo, entre otros, motivaron un largo y sostenido debate en torno a la necesidad de introducir reformas en el modelo del Estado autonómico, constitucionalizándolo. Junto a ello, desde comienzos del decenio de los ochenta se han producido muchas e importantes transformaciones económicas, sociales y políticas en indudable interrelación: todas las derivadas de la globalización y de la construcción y desarrollo de la Unión Europea; las que son reconocibles en los ámbitos científico y tecnológico y en la ecología, cambio climático y protección del medio ambiente; en la llamada sociedad de la comunicación e información, en los modelos convivenciales familiares y en las relaciones entre los géneros; los factores que han convertido a España en lugar de inmigración — sobre todo antes de la crisis económica- - y en escenario de un cada vez más intenso multiculturalismo... Se trata, 
sin duda, de muy poderosas razones para que desde los ámbitos institucionales autonómicos, no sin gran debate sobre su conveniencia, se decidiera finalmente a comienzos de la pasada década, pese a la oposición suscitada en determinados sectores políticos, dar salida a tanta presión y emprender la tarea de poner al día los Estatutos, estableciendo los fundamentos, según se declaraba, para el desarrollo de nuevas y más intensas políticas públicas.

Estamos, pues, en una penúltima fase del Estado autonómico de la que habría que recordar los aspectos más destacados de las reformas estatutarias del último decenio. Caso aparte y singular, precedente inmediato de este periodo, fue el fuerte embate soberanista que supuso la frustrada proposición de reforma del Estatuto de autonomía del País Vasco, la «Propuesta de reforma de estatuto político de la comunidad de Euskadi», más conocida como «Plan Ibarretxe», que fue rechazada por el Congreso de los Diputados el 1 de febrero de 2005, en la que el planteamiento que latía detrás del concepto de «pueblo vasco» generaba una contradicción radical entre este proyecto y la Constitución.

Se ha venido destacando con buenas razones que para avanzar en una reforma del modelo de organización territorial del Estado debería haberse consensuado previamente una reforma constitucional que constitucionalizara el Estado autonómico conforme a un modelo racionalizado de acuerdo a la evolución seguida y en el marco del consenso fundamental que pudiera articularse a partir de las nuevas realidades políticas. Desde luego, en términos analíticos la reforma constitucional es cada vez más necesaria en muchos ámbitos, especialmente en lo relativo a la estructura territorial. Sin embargo, políticamente no fue posible, y esa reforma sigue siendo recurrentemente evitada por temor a que sea más un motivo de desencuentro que un factor de encuentro y de renovación del consenso que dio lugar a la Constitución en 1978. Por ello, en buena medida, los impulsos reformadores en este ámbito se desplazaron a la reforma de los Estatutos de autonomía con una lógica de actualización del estado autonómico a partir de la consolidación de las experiencias de autogobierno de las CCAA, pero generando notables disfunciones, especialmente ante las pretensiones cada vez más radicales del nacionalismo, como vendría a poner de relieve finalmente la STC 31/2010 sobre el Estatut y las reacciones que siguieron. Cabe añadir, por otra parte, que no hubiera sido suficiente — ni lo sería hoy — la limitada, limitadísima, reforma constitucional que en este terreno hubiera podido auspiciar el Gobierno socialista de José Luis Rodríguez Zapatero mediante la consulta que en Marzo de 2005 dirigiera al Consejo de Estado: la reforma del Senado, para convertirlo en una auténtica Cámara de representación territorial; la recepción en la Constitución del proceso de construcción europea, y la inclusión de la denominación de las Comunidades Autónomas (además de la cuestión relativa al orden sucesorio para eliminar la preferencia del varón sobre la mujer). Pese al documentadísimo informe del Consejo de Estado de 16 de Febrero de 2006, muy acertado en determinados aspectos, sus conclusiones no ofrecen sustento suficiente para la reforma constitucional que España necesita. 
La primera reforma estatutaria que se materializó en el tiempo fue la de la Comunidad Valenciana (Ley Orgánica 1/2006, de 10 de abril), muy limitada, especialmente por lo que se refiere a las competencias, por lo que se propician nuevas modificaciones para adaptar el Estatuto a las previsiones contenidas en el nuevo Estatuto catalán, reformado también aquel mismo año. El nuevo Estatuto de Cataluña (Ley Orgánica 6/2006, de 19 de julio) se situó en una posición paradigmática como modelo al que han seguido por emulación, con distintas intensidades, otras reformas estatutarias, muy destacadamente la andaluza (Ley Orgánica 2/2007, de 19 de marzo). Cabe subrayar que este «factor emulación» ha sido poderoso y tenía capacidad suficiente, a mi juicio, para cumplir un papel positivo, en tanto que tendía a asegurar unos niveles básicos de convergencia en las reformas. Tal función hubiera podido incidir en la puesta en pie de un paradigma reformado de integración del modelo territorial del Estado desde la apertura a una más compleja y potencialmente creativa diversidad, incluso con menores riesgos de «asimetrías», algo que ciertamente se revelaba difícil de alcanzar debido al esperable inconformismo nacionalista y su recurrente presión para tomar progresiva distancia de otros territorios. Una presión que estuvo simultaneada en Cataluña, desde hacía años, con un claro proceso de nation building, que desde 2010 se transmutó abiertamente en un tránsito progresivo hacia el secesionismo, incluso unilateral y al margen de la legalidad constitucional y estatutaria. Todo ello dio al traste con esta posible dinámica. [ Pudiéramos decir - tomando un tanto libremente la célebre carrera entre la liebre y la tortuga que popularizara a partir de la fábula el conocido, celebrado y gráfico artículo de Javier Pradera- que la liebre política nacionalista, alcanzada por la tortuga de las autonomías comunes, ya no aspira a volver a sacar distancia sino que quiere aprovechar la ventana de oportunidad que le ha abierto la crisis económica, social, política y territorial, para abandonar la carrera y pretender establecerse unilateralmente en su república independiente].

Las materias que han estado en discusión en las reformas estatutarias han sido muchas. Destacan algunas que tienen que ver con cuestiones identitarias, principiales y dogmáticas, como son la definición de la propia identidad o el establecimiento de una carta de derechos y deberes; otras relativas al ámbito competencial, como la definición y establecimiento de las competencias en los Estatutos, así como las referencias a las transferencias vía artículo 150.2 CE y la modificación de leyes generales del Estado; respecto a las cuestiones institucionales, dejando de lado la mejora de las instituciones de autogobierno que se procuran en las reformas, han sido especialmente problemáticas las relativas al Poder Judicial en la respectiva CA (sobre todo, los Consejos de Justicia), las relaciones Estado-CCAA y la participación en las decisiones relacionadas con la UE; y, finalmente, el sistema de financiación. Sería imposible, con la brevedad que imponen estas reflexiones generales, dar cuenta más precisa de todas ellas.

Así las cosas y con la dinámica anteriormente expuesta, el Estado autonómico ha llegado a incardinarse en su evolución, sin ninguna duda, en la categoría matriz de 
los Estados federales y de tal manera es materialmente considerado por los más reputados estudiosos del federalismo. La lógica del Estado autonómico es la misma que la de un Estado federal, se considere ésta desde la perspectiva de los fines estatales unitarios a alcanzar, desde el aseguramiento del autogobierno, desde la racionalidad de la distribución competencial y la financiación, desde los mecanismos de resolución de conflictos, desde los instrumentos de colaboración y cooperación, o desde la participación de los entes autónomos en la formación de las decisiones estatales. El Estado español ha tendido a funcionar progresivamente, con su problemas y deficiencias, "como si de un Estado federal se tratara», pudiéndose decir que «constituye un supuesto de prefederalismo» que se mantiene «en la órbita o campo de atracción del Estado federal» (Pedro Cruz Villalón). Hace ya muchos años, también Peter Häberle caracterizó al Estado autonómico como una forma de «protofederalismo», y Gumersindo Trujillo, entre otros muchos autores, se encargó de apreciar en toda su extensión e intensidad la lógica federal que lo ha impulsado, lo alimenta y explica. Eliseo Aja ha culminado precisamente este enfoque con el claro y penetrante análisis general que hace en su libro «Estado Autonómico y reforma federal».

Sin embargo, el Estado autonómico no es formal ni propiamente un Estado federal acabado. En España llevamos mucho tiempo inmersos en un proceso de federalización en curso y, por tanto, incompleto. De ahí que la reforma que eventualmente se emprenda deba tener un sentido federativo de culminación, tipo bolding togheter, que no pudo tener en el proceso constituyente de 1978 ni ha tenido tampoco antes en nuestra historia. Como hemos precisado y ha destacado J. Pérez Royo, no existió entonces una voluntad expresa constituyente en este sentido y por ello el Estado autonómico no dispone de la específica legitimidad que aquella voluntad aportaría ni tampoco de la plenitud y coherencia de todos los rasgos organizativos y de funcionamiento de la forma federal. Al contrario, presenta importantes carencias e incoherencias en su estructura, articulación y funcionamiento, ampliamente estudiadas por la doctrina académica y puestas de relieve en la vida la política, todo lo cual ha acabado afectando, en tiempos de aguda crisis, a que también venga adoleciendo de una merma en su legitimidad de ejercicio (legitimidad que, sin embargo, ha sido muy alta hasta finales de los años noventa). A todo ello se suma el importante desgaste que el Estado autonómico está sufriendo desde la pasada década en un doble frente: de un lado, el proveniente del nacionalismo radical, excluyente y secesionista, que en su desigual conjunto ha crecido exponencialmente en Cataluña en los últimos años (sobre todo desde la STC 31/2010 sobre el Estatut), permaneciendo latente, por otro lado, el independentismo que repuntó y se expresó con fuerza en el País Vasco a principios de la década de 2000 con el llamado «Plan Ibarretxe» y que obviamente podría resurgir otra vez bajo otras formas y circunstancias; de otro, porque desde determinadas posiciones nacionalistas de la derecha hispana —aunque éste constituya un riesgo menor, mínimo, pero un gran hándicap para emprender reformas - se viene presentando interesadamente al modelo autonómico como una organización territorial en buena medida responsable de la crisis económica y de un pretendido caos organizati- 
vo, fundamentalmente por el costo de su mantenimiento y por sus «duplicidades»; mensaje que está teniendo también un no desdeñable calado en un amplio sector de la opinión pública, contribuyendo de esta manera a prestar «razones políticas» aparentes a los planteamientos reformistas que pretenden una hoy por hoy imposible recentralización del modelo.

\section{6. ¿HACIA UNA REFORMA DE LA CONSTITUCIÓN? ALGUNAS CLAVES EN SENTIDO FEDERAL}

De acuerdo con cuanto antecede, considero que la Constitución de 1978 está necesitada de una reforma profunda. Los partidos políticos más renuentes a abrir este proceso debieran asumir que ya no puede demorarse más, así como que el resultado tiene que ser ineludiblemente el fruto del diálogo y del pacto, de grandes cesiones y transacciones recíprocas, de compromisos compartidos, porque jurídicamente así lo exige el procedimiento de reforma y, sobre todo, porque políticamente la reforma tiene que servir para todos como marco para articular democráticamente las condiciones básicas de vida en común en toda España. El objetivo de la reforma ha de ser adecuarla a la realidad de nuestro tiempo para poder asegurar su normatividad y, por tanto, su eficacia. Desde luego una reforma constitucional no tiene per se propiedades taumatúrgicas, pero un pacto constitucional renovado por el poder constituyente-constituido con una voluntad clara sobre un modelo específico de cuño federal, permitiría abrochar constitucionalmente la gran asignatura pendiente de nuestra historia sobre la organización, articulación e integración territorial del Estado español.

Es evidente pero no inútil recordarlo una vez más: la realidad ha cambiado extraordinariamente en las casi cuatro décadas de vigencia de la Constitución. Dejando a salvo las dos únicas reformas puntuales que se han producido por imperativos provenientes de la UE (las de 1992 y 2011), no ha sido propiamente reformada para adecuarla al conjunto de las necesidades de nuestros días. Esto contrasta llamativamente con los países de nuestro entorno, donde es práctica normal y frecuente realizar reformas constitucionales cuando son necesarias. Lo que sirvió en 1978 en la transición de la dictadura a la democracia hoy resulta manifiestamente insuficiente en muchos aspectos por el carácter sistémico que cada vez más adquiere la necesidad de la reforma al no haberse llevado a cabo reformas parciales previas. También, por otra parte - y aunque este no sea a mi juicio un argumento determinante-, es muy pertinente y adecuado que las «generaciones vivas» participen en este proceso y que su voz pueda ser escuchada y tenida en cuenta en la elaboración de la norma suprema que regula la convivencia de todos, contrariamente a lo que otros autores afirman (así, por ejemplo, M. Aragón).

Los motivos para la reforma son sustancialmente políticos, no tanto técnicos, pero son los primeros los que marcan la necesidad de la reforma y por ello deben ser atendidos de forma prioritaria. Interesa destacar también que hablo de pacto y no 
tanto de consenso, que también, por supuesto. La dimensión del consenso originario alcanzado en la Transición para poner en pie un orden democrático pleno y de nueva planta no debe entenderse hoy como un requisito imprescindible, en el sentido de que tenga que ser igual o superior — como suele decirse y por deseable que seaal alcanzado durante aquel proceso constituyente. Hoy no necesitamos un proceso constituyente. No lo necesitamos porque los grandes principios, los valores, los elementos sustanciales de reconocimiento y protección de los derechos, los poderes divididos y sus relaciones recíprocas, así como las grandes instituciones, están bien establecidos y ordenados en términos generales en la Constitución. Tampoco hay una situación política tal que así lo requiera ineludiblemente, pese a la extraordinaria gravedad del desafío soberanista alimentado por algunas élites y determinados sectores del nacionalismo catalán más exacerbado. Necesitamos una reforma, amplia y profunda, pero no solo por este conflicto, sino porque así lo demanda el conjunto del sistema político. Y esta reforma requiere el cumplimiento de los procedimientos establecidos por la propia Constitución, es decir, los concretados en los artículos 167 y 168 , que lo que exigen son específicas mayorías de $3 / 5$ y $2 / 3$ respectivamente, según haya de aplicarse el procedimiento ordinario o el agravado. El consenso debe entenderse más como un elemento positivo de orientación y aspiración para el diálogo y el debate, tanto en la metodología como en los contenidos, en la búsqueda de una reforma fraguada de la manera más compartida posible. El consenso no puede ser así un punto de partida sino, en su caso, un método y un logro que se alcanza a lo largo del proceso de reforma, deseable para sumar a cuantas más fuerzas políticas mejor y para conseguir la aceptación de la ciudadanía que podría manifestarse ocasionalmente mediante el referéndum en la reforma ordinaria y que sería preceptivo en todo caso en la agravada. Pero no puede negarse que la culminación de la reforma sería plenamente legítima con la consecución de las antedichas y respectivas mayorías. Así lo he venido argumentando en recientes debates en diversos foros y así ha llamado la atención sobre ello Eliseo Aja en un artículo de prensa en el que apreciaba comparativamente que la Constitución de 1978 se aprobó por 325 votos a favor, esto es, por consenso, en tanto que la mayoría que la Constitución exige sería de 210 para el caso de la reforma ordinaria y de 232 para la agravada. Una evidencia para tomar en consideración que no debemos hacernos más difícil la reforma de lo que prevé la propia Constitución.

No se me escapa, obviamente, que la mayor dificultad estriba en conseguir la aceptación mayoritaria en los territorios que tienen la «asimetría política» de un arraigado nacionalismo, hoy en buena parte independentista. Es verdad que quienes se han caracterizado por sostener un independentismo irredento nunca van a ser convencidos por ninguna reforma, al menos por ninguna que no abra la puerta inmediata a la independencia reconociendo el derecho a la secesión. Sin embargo, el número de nacionalistas de esta condición es mucho menor del que, hoy por hoy, conforma el nacionalismo moderado junto con la mayoría no nacionalista. Y aquí entiendo que está la clave sobre una opción de encuentro, con una buena reforma, que se mantenga 
en el espectro de una profunda descentralización política en un estado compuesto y pluralista, como revelan los datos demoscópicos disponibles que manifiestan la existencia de una neta mayoría sumando a quienes están a favor de mantener la estructura del Estado tal como está, aquellos que consideran que debería contemplarse un mayor nivel de autogobierno y quienes son partidarios de una reforma en sentido federal que racionalice nuestro actual Estado de las autonomías.

Pero ¿en qué aspectos concretos debería centrarse la reforma constitucional? En este espacio no podemos desarrollar detalles, pero sí apuntar algunas claves ceñidas a la organización territorial del Estado, aunque considero que también deberían ser objeto de reforma algunas otras cuestiones: las relativas a la mejora del sistema de protección de derechos sociales básicos; el artículo 135 de la Constitución para incorporar un principio de «estabilidad social» que asegure en la distribución del gasto público, incluso en situaciones de crisis, un nivel adecuado de financiación y sostenimiento de los servicios y prestaciones sociales; algunas cuestiones concernientes a los derechos fundamentales y a determinados derechos del Capítulo III del Título I para mejorar su sistema y adecuarlos al transcurso del tiempo; la mejora del sistema y los instrumentos de participación política, así como introducir elementos de transparencia y de regeneración democrática en la composición y funcionamiento de órganos e instituciones públicas; el orden sucesorio a la Corona, eliminando la preferencia del varón sobre la mujer y racionalizar otros aspectos del Título II; mejorar determinados aspectos de la regulación de órganos constitucionales o con relevancia constitucional y también de organizaciones con esa misma relevancia; sin olvidar los procedimientos de reforma constitucional del Título $\mathrm{X}$, que sería preciso modificar en un sentido menos rígido, especialmente el procedimiento agravado, con el objetivo de facilitar que la Constitución pueda reformarse siempre que sea necesario y exista una amplia mayoría política y ciudadana que así lo demande.

Hablo de reforma «en sentido federal» porque importa la racionalización, mejora e incorporación en la Constitución de nuestro modelo de organización territorial, reordenando el Estado autonómico en esta dirección en tanto que es, de facto, federal, por haber evolucionado con su lógica y con una estructura asimilable en términos generales a los sistemas federales hoy existentes, tan diferentes entre sí por otra parte. Tras la experiencia evolutiva del Estado autonómico, hoy se dan las condiciones para ese nuevo pacto con tal orientación (que no se daban en el proceso constituyente), aunque se trate de una operación especialmente delicada y compleja. Si bien el «proceso autonómico» abierto con la Constitución se ha venido desarrollando materialmente, sin ninguna duda, en la órbita del federalismo, con muchas de sus técnicas y alcanzando resultados comparables a los estados federales en el grado de autogobierno de los entes territoriales que lo componen, su forma no es propiamente federal. No lo es - insisto- porque no existió una voluntad expresa constituyente en ese sentido ni tampoco, por ello, el modelo resultante tiene la plenitud y coherencia de todos los rasgos organizativos y de funcionamiento de la forma federal. Por ello la dirección de la reforma no puede ser otra sino la que marca el federalismo. Un modelo federal 
constitucionalizado, al que se renunció en 1931 y en 1978 —en buena medida por razones históricas bien conocidas y antes expuestas - sería la desembocadura lógica del proceso hasta ahora seguido y, con la experiencia acumulada, un indudable y simultáneo punto de encuentro, de llegada y de salida, ante las tensiones territoriales que venimos arrastrando desde hace más de un siglo y ante la conflictividad tan fuerte que hoy vivimos. Podríamos dar así respuesta al proceso evolutivo seguido en la práctica política desde hace casi cuatro décadas de manera muy desordenada, bastante desestructurada y permanentemente abierta, siempre dependiente de la intervención excesiva de un Tribunal Constitucional convertido a la fuerza, malgré lui, en un órgano delimitador de las competencias y, últimamente, con la reforma de la LOTC de 2015, incluso de potencial intervención directa en los más intensos conflictos políticos territoriales, colocándolo así de pleno en actor en el escenario de la política; una respuesta que poniendo fin al confusionismo dominante en el Estado autonómico, sobre todo en los ámbitos de la distribución competencial, de la financiación y de las relaciones intergubernamentales, garantice tanto la riqueza de la diversidad y pluralidad de España, con un autogobierno de calidad, como su unidad y la solidaridad interterritorial.

Todo ello requeriría adoptar muchas medidas concretas, cuyo desarrollo no puede hacerse aquí, ampliamente estudiadas por la doctrina. Estas serían las más importantes: incluir en la Constitución, como sugiriera el Consejo de Estado en su citado informe de 2006, mención expresa a todas y cada una de las CCAA que integran el Estado, por el orden de su constitución en Comunidad Autónoma y, en su caso, en castellano y en la lengua propia; podría ser adecuada una cláusula en el Título Preliminar alusiva al naturaleza federal del Estado junto a su carácter social y democrático de Derecho; regulación del Senado como Cámara que tanto por su composición, estructura y funciones, represente real y eficazmente a los territorios, las nacionalidades y regiones, sea con estas u otras denominaciones; es fundamental que se realice un reconocimiento pleno de las singularidades y sus efectos y consecuencias: lengua propia, cultura, foralidad, organización territorial, peculiaridades históricas de derecho civil, insularidad y ultraperifericidad; como especial contribución a una política de integración, además, podrían «desconcentrarse» en los territorios determinados órganos e instituciones centrales (con excepción de la Jefatura del Estado y del Congreso de los Diputados, que estarían radicados en la capital del Estado); llevar a la Constitución los principios de lealtad y colaboración, así como los aspectos sustanciales de los mecanismos e instrumentos de colaboración y cooperación intergubernamental tanto verticales, multilaterales como bilaterales, y horizontales entre las CCAA, además de los procedimientos compartidos puestos en pie por los estatutos llamados «de segunda generación»; rediseñar el sistema de distribución de competencias entre Estado y CCCA conforme a un modelo más claro, recogiendo en la Constitución las facultades competenciales concretas del Estado a partir de la tarea ya realizada por el Tribunal Constitucional y por los estatutos surgidos de las más recientes reformas al concretar las competencias autonómicas; reducir al máximo las 
competencias compartidas en evitación de conflictos; precisar el alcance y el procedimiento de definición y regulación de las bases, entendiéndolas como principios o mínimo común normativo que debe establecerse por regla general mediante normas con rango de ley, como rezaba el artículo 111 del Estatut, parcialmente declarado inconstitucional y nulo por la STC 31/2010 (entendiendo que esa regulación solo puede estar en la Constitución); y establecer como cláusula residual que todo lo no atribuido al Estado por la Constitución sea de competencia autonómica; fijar también en la Constitución los elementos fundamentales y básicos del sistema de financiación conforme a un modelo que garantice, además de la suficiencia y la corresponsabilidad, la solidaridad interterritorial en términos de equidad, manteniendo el peculiar sistema de conciertos garantizado por la Disposición Adicional Primera al País Vasco y a Navarra, en tanto que hecho diferencial, pero introduciendo una modificación que estableciera un mandato de «actualización» del régimen foral dirigido a hacer posible, con una nueva metodología de determinación del cupo vasco y de la aportación navarra, una contribución ajustada que no genere desigualdad y que satisfaga las exigencias de solidaridad interterritorial; y establecer una mayor garantía de la autonomía local y de la suficiencia y sostenibilidad en su financiación, distinguiendo los municipios según su carácter urbano o rural y potenciando el impulso a la cooperación intermunicipal. La Constitución necesita también disponer de reglas adecuadas para la articulación de España en la UE a partir del pluralismo territorial interno (introducción de la cláusula europea en la misma línea que ya lo han hecho otros países, como Alemania).

\section{REFERENCIA ESPECIAL A LA CUESTIÓN CATALANA}

Una última reflexión en referencia especial a la cuestión catalana, extensible a otros planteamientos soberanistas. Puesto que esto se discute, ¿puede el federalismo con sus principios y técnicas dar respuesta adecuada y suficiente a las demandas que provienen de Cataluña y que el secesionismo viene sosteniendo para «justificar»su postura? La respuesta — que aquí extracto— es, a mi juicio, claramente afirmativa y de ello me he ocupado más en extenso en un Congreso celebrado en Bilbao (Ways of Federalism Conference. Claims for Secession and Federalism. The Spanish Case in the Light of the Federal Experience, 25-26/11/2015, Universidad del País Vasco, cuyas actas están en proceso de publicación). Ateniéndonos a las alegadas justificaciones que para alentar y pretender la independencia ofrecen sus promotores, plasmadas en el mismo Libro Blanco de la Transición Nacional de Cataluña elaborado por el llamado Consejo Asesor para la Transición Nacional, las reivindicaciones que expresan serían por entero susceptibles de ser encauzadas democráticamente mediante una reforma federal en los términos antes expuestos. Así, en sustancia, la caracterización política de Cataluña; mejorar las condiciones de vida de los catalanes, donde se garantice la cohesión social y se promueva el bienestar; alcanzar un nivel de autogobierno pleno y de cali- 
dad, acabando con la invasión competencial estatal; mejorar la democracia; y atender la demanda de una financiación justa y equitativa en un marco de solidaridad y equidad.

Desde esta perspectiva, carece de toda justificación la dimensión externa en la que se viene esgrimiendo en Cataluña el neologismo «derecho a decidir» (en realidad una «idea talismán», como la llama Alberto López Basaguren, inventada por los independentistas que encubre el derecho a la autodeterminación para amparar la secesión). Porque Cataluña ni es colonia, ni está ocupada militarmente por potencia extranjera, ni es un pueblo oprimido ni está sometido a una violación sistemática de derechos humanos, que son los supuestos en los que el Derecho internacional ampararía la secesión de un territorio. Antes al contrario, goza de una amplia capacidad de autogobierno en el marco de un sistema plenamente democrático, tanta que suele considerarse prácticamente de manera unánime por los estudiosos en la materia como equiparable o superior a la que disfrutan muchos estados miembros de Estados federales de nuestro entorno; $y$, por supuesto, sus habitantes gozan del avanzado y consolidado sistema de reconocimiento y protección de derechos y libertades fundamentales que establece la Constitución española en su Título I y, en su marco, la ciudadanía catalana dispone de amplias vías y posibilidades participativas en el ámbito político y en otros, como se recogen en la Constitución y en su Estatuto, que vienen siendo ejercidas con normalidad a lo largo de décadas. Como nacionalidad organizada en Comunidad Autónoma, en Cataluña, notoriamente, está democráticamente garantizada su capacidad y derecho a decidir con plenitud en su dimensión interna por la Constitución y su Estatuto de Autonomía.

De la identificación de existencia de una nación cultural con autonomía, tout court, no nace el derecho de un pueblo a configurarse como sujeto político soberano ni, en consecuencia, el derecho a decidir sobre la secesión. Cataluña es una nacionalidad así reconocida en el Estado español, con un significado simbólico de respeto identitario y de integración similar al concepto de nación cultural. Cataluña no alberga, como por otra parte suele ser común en las sociedades actuales de nuestro globalizado mundo, un pueblo homogéneo diferenciado y aparte, sino mestizo y complejo, que comparte muchos rasgos culturales con el conjunto de los pueblos de España, internamente muy diverso y cada vez más por el fenómeno de la inmigración, aunque sin duda con singularidades compartidas, entre las que destacan la lengua, rasgos culturales definidos, especificidades jurídicas e institucionales y peculiaridades históricas, que son apreciadas, respetadas y amparadas por el Estado, como establece la Constitución. Cataluña, en definitiva, con tales características, es reconocida como sujeto político constituido, dentro del Estado español, en Comunidad Autónoma, precisamente como nacionalidad, de acuerdo con la Constitución (según se recoge en el art. 1.1 de su Estatuto) y tiene reconocidas y garantizadas sus singularidades por el bloque de la constitucionalidad (arts. 5 y 6 y concordantes de su Estatuto). En correspondencia con todo ello, puede constatarse que la mayor parte de la población que lo compone tiene identidades compartidas, en tanto que manifiesta ampliamente un sentimiento 
simultáneo de pertenencia a España y a Cataluña, como revelan con meridiana claridad los estudios demoscópicos disponibles.

El llamado «derecho a decidir» que sin duda tiene Cataluña, por estas razones, entendido en sentido propio, lo es internamente en el marco de la integridad territorial del Estado español y de acuerdo con su ordenamiento constitucional y estatutario, pero no tiene reconocido derecho a la secesión ni en el ámbito del derecho internacional ni en el interno, ni éste podría deducirse implícitamente y sin más de los principios inspiradores de la democracia genéricamente invocados y desasidos del respeto democrático a la normatividad constitucional. Precisamente por ello entiendo que no sería posible un referéndum para que solo la ciudadanía de Cataluña se pronunciara «directamente» sobre la independencia, toda vez que un referéndum de estas características no podría hacerse sin reforma constitucional previa que lo habilitase teniendo sistemáticamente en cuenta lo establecido en los artículos 1.2, 2, 9.1, 92, 149.1.32, 167 y 168 CE.

Sin embargo, la Constitución sí que habilita la celebración de un referéndum en el procedimiento de reforma constitucional, respecto de la cual no existe cláusula de intangibilidad alguna en su articulado, tal como ha ratificado en numerosas ocasiones el Tribunal Constitucional, en la que todo puede ser por consiguiente debatido. La reforma constitucional resulta, por esta razón, no solo necesaria sino mucho más deseable y democrática que un referéndum sobre la secesión, en tanto que toda la ciudadanía afectada (y no solo la de una parte) podría debatir y decidir de manera compleja sobre las distintas posibilidades y alternativas de integración política, contrariamente a la decisión forzosamente extrema, simplificadora, binaria e irreversible de un referéndum, que seguramente estaría muy influido además por datos poco contrastados, sentimientos exacerbados derivados de la coyuntura política e intereses insuficientemente tenidos en cuenta (como, por otra parte, han revelado los procesos referendarios más recientes y significativos de nuestros días en otros países y en la Unión Europea con el Brexit).

Desde esta perspectiva, por tanto, lo que sí es necesario y posible es proceder a algo más complejo y democrático, como redefinición de las condiciones básicas de vida en común dentro del sistema político y jurídico global de España definido en la Constitución, con respeto y amparo de las singularidades, porque la gran mayoría de la ciudadanía catalana, como la española en su conjunto, lo que pretende es mejorar su situación y su interrelación en todos los ámbitos. Tengamos presente que la demanda ciudadana de cambio y regeneración democrática es ampliamente compartida en toda España, y la relegitimación, las inconsistencias y problemas de estructura, articulación y funcionamiento del Estado autonómico que deben ser abordadas y resueltas afectan a todos los territorios, como antes se ha expuesto, aunque sea en diferente medida. Todo ello, incluyendo el reconocimiento con suficiencia de la singularidad catalana (dejando de lado la soberanía, que hoy, en la etapa postnacional, es ineludiblemente compartida de facto en todos los niveles), sería en su caso susceptible de ser adecuada y democráticamente encauzado para su resolución mediante los principios 
y las técnicas del federalismo. Porque tengamos presente que el federalismo es ideología y técnica democrática, pero no partidaria, que multiplica, profundiza y potencia la democracia con el reparto vertical del poder y su integración para la consecución de objetivos comunes, realizando una síntesis dialéctica entre unidad y autonomía, entre igualdad y diversidad (Manuel García Pelayo), haciendo posible lo que constituye su esencia: autogobierno y gobierno compartido. Y que también, por todo ello, puede y debe incorporar elementos de reconocimiento e integración. Autonomía e interdependencia en equilibrio es lo que permite la unidad compleja característica del federalismo.

Entiendo que las consideraciones que anteceden y el perímetro trazado, aunque con trazo grueso, sustentan elementos suficientes para conducir a la apertura de las negociaciones políticas pertinentes para tratar de converger en el planteamiento de una reforma constitucional en los ámbitos social, de calidad democrática y de organización territorial en clave federal. Una reforma que sea democráticamente satisfactoria para todos y nos permita alejarnos de las fracturas sociales, políticas y territoriales que hoy padecemos con injustificado exceso. Obviamente la reforma desembocaría en un referéndum de todos los españoles y daría lugar a una reforma estatutaria en Cataluña que igualmente sería sometida a referéndum de la ciudadanía catalana, como ocurriría también en los demás territorios. Es precisamente en esta reforma estatutaria en la que se podría definir su condición política dentro del marco constitucional, incluso apelando al concepto nacional, que no coincide con estatal, toda vez que la soberanía se residencia en el conjunto del pueblo español, en la que, por tanto, todos los pueblos que integran España y toda la ciudadanía participan a través de los mecanismos estatales establecidos por la Constitución, los Estatutos de Autonomía y la legislación específica.

Para dar cauce a las aspiraciones nacionales de Cataluña (no a las de la minoría independentista, naturalmente) considero que no es preciso acudir a conceptos difusos que más que contribuir a resolver o encauzar la cuestión catalana a lo que pueden conducir es a enturbiar el debate y situarlo en el campo discursivo del nacionalismo, dejando en la imprecisión más absoluta las consecuencias jurídico-políticas sobre las cuestiones materiales concretas que realmente importan y que se ven interpeladas (distribución competencial, financiación, instituciones de gobierno compartido, relaciones intergubernamentales...), pudiendo además servir al secesionismo como apoyatura pro futuro en una historia interminable de reivindicación soberanista. Es el gran riesgo que se corre si centramos indiscriminadamente el debate en el concepto «nación», la apelación a la «nación de naciones» y la «plurinacionalidad», pretendiendo llevar estos elementos de manera expresa a la reforma constitucional. Con independencia de otros argumentos sobre nuestra realidad histórica y política que no avalan precisamente la generalización de este esquema, no resulta extraño que no sea éste el lenguaje comparado de las constituciones, que por su propia razón de ser han de centrarse en construir y constituir lo común, lo que une, el marco de encuentro plural y de articulación de las condiciones de vida básicamente compartidas por toda 
la ciudadanía. La presencia del término «plurinacional» en algunas constituciones, como las de Bolivia y Ecuador — que no son Estados federales sino unitarios, pero con cierto grado de descentralización - se explica por la existencia en estos países de minorías étnicas, las naciones y pueblos indígenas y comunidades afrobolivianas y afroecuatorianas, a las que se reconocen una serie de derechos y un cierto grado de autogobierno.

Las aspiraciones nacionales de Cataluña, en la dimensión cultural identitaria y autoorganizativa que se reivindica desde posiciones más moderadas y no abiertamente soberanistas, podrían tener cauce adecuado en una reforma con las claves anteriormente expuestas, sin seguir el abrupto camino de un debate generalizado sobre la plurinacionalidad (que esconde a su vez el debate sobre la soberanía), que sería divisorio y quizás impeditivo de cualquier acuerdo suficientemente compartido. Partiendo del reconocimiento de la unidad de España y de residenciar la soberanía en el conjunto del pueblo español, se podría incorporar —bien en el Título Preliminar o en el Título VIII- el principio de organización federal y, simultáneamente, dejar la denominación oficial específica de las Comunidades que la integran, así como el establecimiento de su orden político propio, a la constitución o estatuto de cada Comunidad, dentro del marco establecido por la Constitución federal. Constitución propia o Estatuto que no tendría que depender de la aprobación de las Cortes Generales (como ocurre en los Estados federales), pero que sí estaría sometido — también en sus reformas - a un eventual control de constitucionalidad de carácter previo, con un plazo que debería ser muy corto y antes de su refrendo popular, a los efectos exclusivos de garantizar el respeto al marco constitucional federal.

Una última y breve reflexión. La metodología de la reforma es especialmente importante en un sistema como el nuestro, con una amplia parte de la clase política profundamente temerosa o reacia a abrir ese proceso y con unos procedimientos de reforma de dificultad extrema. Pero el más importante y negativo escollo para afrontar los problemas lo produce el inmovilismo, en exceso arraigado en la mente de muchos políticos y no pocos analistas. Algunos dicen que no hay consenso para emprender la reforma, ipero es que esto no puede comprobarse, ni mucho menos generarse, si los partidos no se sientan a la mesa a hablar sinceramente sobre ello! Hoy toca estar a la altura de lo que las circunstancias demandan, como lo estuvo en su día la clase política de la Transición. Para ello, con independencia de que previamente, en su caso, pudiera haber una mesa de partidos exploratoria o cualquier otro instrumento político similar que «perimetrara» el posible alcance de la reforma tras un diagnóstico preciso y evaluativo del Estado autonómico, debería crearse una Subcomisión de estudio de la reforma constitucional en el seno de la Comisión Constitucional del Congreso que sin prisas vaya abriendo este camino. Hay que iniciar el proceso de diálogo y búsqueda de los acuerdos necesarios para delimitar los aspectos compartidos de la reforma, con la comparecencia de expertos y la petición de los correspondientes informes a los órganos e instituciones que se determinen, a las 
Comunidades Autónomas y a las Ciudades con Estatutos de Autonomía, elaborando un estudio de conclusiones a tales efectos que permita, en su caso, abrir la ventana de la reforma sobre cauces seguros y ampliamente compartidos.

Tengamos muy presente las claras lecciones que nos ha dado nuestra historia y la riqueza de las experiencias vividas en la evolución del Estado autonómico, tanto las positivas como las negativas. Todo ello, junto con el federalismo comparado y el ingente trabajo desarrollado por nuestros iuspublicistas nos puede aportar la luz necesaria para alumbrar el marco político y jurídico que establezca el equilibrio necesario entre los ámbitos y mecanismos de autogobierno y gobierno compartido y la integración de un país tan plural como España, tan lleno de potencialidades.

\section{NOTA BIBLIOGRÁFICA}

Aja, Eliseo, Estado autonómico y reforma federal. Madrid, Alianza Editorial, 2014.

- «MAYORÍAS Y CONSENSO EN LA REFORMA CONSTITUCIONAL», «elPeriódico», Miércoles, 07/12/2016, actualizado el 08/12/2016).

Aja, Eliseo; García Roca, Javier; Montilla, José Antonio; Díez Bueso, Laura, «Reflexiones sobre una posible reforma constitucional del sistema autonómico», en Informe Comunidades Autónomas 2015. Barcelona, Institut de Dret Públic, 2016.

Aragón Reyes, Manuel, «La construcción del Estado Autonómico», Revista General de Derecho Constitucional, 1, 2006. pp. 15-38 [también en Cuadernos Constitucionales de la Cátedra Fadrique Furió Ceriol, 54/55, 2006, pp.75-95.

- «La reforma Constitucional». Editorial. Revista General de Derecho Constitucional 24 (2017).

Arroyo GiL, Antonio, «Cataluña en el Estado Autonómico: Derecho y Política». El Cronista del Estado Social y Democrático de Derecho, n. ${ }^{\circ}$ 70, pp. 10-27.

Balaguer Callejón, Francisco, «La constitucionalización del estado autonómico». Anuario de Derecho Constitucional y Parlamentario, n. ${ }^{\circ}$ 9, 1997.

— «Los hechos diferenciales y la evolución del Estado autonómico». En A. Pérez Calvo (Coord.): Estado, Nación y Soberanía (Problemas actuales en Europa). Madrid, Ed. Temas del Senado, 2000.

- «LA ORganización TERritorial DEl Estado y LAS COMPETENCIAS DE LAS Comunidades Autónomas». En F. Balaguer Callejón (CoOrd.), Gregorio Cámara Villar, Juan Fernando López Aguilar, María Luisa Balaguer Callejón, José Antonio Montilla Martos, Manual de Derecho Constitucional, Vol. I, Capítulo XII, Madrid, Tecnos, 2016.

Blanco Valdés, Roberto Luis, Los rostros del federalismo. Madrid, Alianza Editorial, 2012.

- El laberinto territorial español. MADRID, Alianza Editorial, 2014. 
Cruz Villalón, Pedro, «La estructura del Estado, o la curiosidad del jurista persa». Revista de la Facultad de Derecho de la Universidad Complutense, n. ${ }^{\circ} 4,1981$, pp. 5363; después incluido en su libro La curiosidad del jurista persa, y otros estudios sobre la Constitución, Madrid, Centro de Estudios Políticos y Constitucionales,1999, pp. 381 a 394.

CaAmaño, Francisco, Democracia federal. Apuntes sobre España. Madrid, Turpial, 2014.

Cámara Villar, Gregorio, «El principio y las relaciones de colaboración entre el Estado y las Comunidades Autónomas». ReDCE (Revista de Derecho Constitucional Europeo), n. ${ }^{\circ}$, Enero-Junio 2004, en http://www.ugr.es/ redce/, apartado 2,9.

— «La propuesta andaluza de federalización del Estado». En Juan Montabes y Carmen Ortega (Coordinadores) Anuario Político de Andalucía 2014, Sevilla, Centro de Estudios Andaluces, Consejería de la Presidencia y Administración Local, 2015, pp. 251-267.

— "Federal Amendment in Spain v. Secession in Catalonia: Can the Constitutional Amendment satisfy the demands that pretend to justify Secession?». En VVAA. Claims for Secession and Federalism. The Spanish Case in the Light of Federal Experience (2nd. WoF Conference - Revisiting the Ways of Federalism and the Horizons of Territorial Autonomy in Spain). En prensa (entregado y aceptado en Abril de 2016).

- «La proyección de los efectos de la STC 31/2010 sobre el Estatuto de Cataluña en otros Estatutos de Autonomía». Estudos em Homenagem ao Professor Doutor José Joaquim Gomes Canotilho, Coimbra, Coimbra Editora, 2012, Vol. II, pp.167192.

De Carreras Serra, Francesc, «Reformar la Constitución para estabilizar el modelo territorial». En La reforma constitucional. ¿Hacia un nuevo pacto constituyente?. Actas de las XIV Jornadas de la Asociación de Letrados del Tribunal Constitucional, Centro de Estudios Políticos y Constitucionales, Madrid, 2009, pp. 47-111.

— «El sistema autonómico español: ¿Existe un modelo de Estado?». En Asimetría y cohesión en el Estado autonómico (Jornadas sobre el Estado autonómico: integración y eficacia). MADRID, MAP, Instituto Nacional de Administración Pública, 1997.

García De Enterría, Eduardo, «Sobre el modelo autonómico español y sobre las actuales tendencias federalistas». Cuenta y Razón, n. ${ }^{\circ}$ 30, octubre de 1987.

García Pelayo, Manuel, Derecho Constitucional Comparado. Madrid, Alianza Editorial, 1987.

Generalitat De Catalunya. Libro Blanco de la Transición Nacional de Cataluña. Síntesis. Generalitat de Cataluña. Barcelona, Departamento de la Presidencia, Entidad Autónoma del Diario Oficial y de Publicaciones, 2014.

GonzÁlez Encinar, José Juan, El Estado unitario-federal. Madrid, Tecnos, 1985.

HëBERLE, Peter, «Comparación constitucional y cultural de los modelos federales», ReDCE (Revista de Derecho Constitucional Europeo), n. ${ }^{\circ}$ 8, Julio-Diciembre de 2007, http://www.ugr.es/ redce/ 
HäBERLE, Peter, «Problemas fundamentales de una teoría constitucional del regionalismo en perspectiva comparada». En Estudios de Derecho Público. Homenaje a Juan José Ruiz-Rico. Vol. II. Madrid, Tecnos, 1997.

López Aguilar, Juan Fernando, Estado autonómico y bechos diferenciales. Madrid, Cuadernos y Debates, Centro de Estudios Constitucionales, 1998.

López Basaguren, Alberto, «Demanda de secesión en Cataluña y sistema democrático. El Procés a la luz de la experiencia comparada». Teoría y Realidad Constitucional, n. ${ }^{\circ} 37,2016$, pp. 163-185.

Montilla Martos, José Antonio, Reforma federal y Estatutos de segunda generación. Cizur Menor (Navarra), Thomson Reuters Aranzadi, 2015.

MuÑoz Machado, Santiago, Informe sobre España. Repensar el Estado o destruirlo. Barcelona, Crítica, 2012.

PÉrez Royo, Javier, La reforma constitucional inviable. Madrid, Los libros de la Catarata, 2015.

Pradera, Javier, «La liebre y la tortuga. Política y Administración en el Estado de las Autonomías». Claves de Razón Práctica, N. ${ }^{\circ} 38,1993$, págs. 24-33.

Rubio Llorente, Francisco, «Rigidez y apertura de la Constitución», en La reforma constitucional. ¿Hacia un nuevo pacto constituyente?. Actas de las XIV Jornadas de la Asociación de Letrados del Tribunal Constitucional. Madrid, Centro de Estudios Políticos y Constitucionales, 2009, pp. 17-40.

SolÉ TurA, Jordi, «Una lectura autonomista y federal del modelo de Estado constitucional». En VV.AA., Federalismo y Estado de las autonomías. Barcelona, Planeta, 1987, pp. 121-165.

SolÉ Tura, Jordi y AjA, Eliseo, Constituciones y periodos constituyentes en España (18081936). Madrid, Siglo XXI de España Editores, 1977.

SOlOzÁbal Echavarria, Juan José: «Una propuesta de cambio federal», en SOLOZÁBAL, Juan José (Ed.): La reforma federal. España y sus siete espejos, Madrid, Editorial Biblioteca Nueva, 2014, libro en el que se analizan también como elementos del panorama comparado los Estados Unidos (Roberto Luis Blanco Valdés), el Reino Unido (Alberto López Basaguren), Alemania (Miguel Ángel Cabellos Espiérrez), Austria (Antonio Arroyo Gil), Canadá (José M. ${ }^{a}$ Castellá Andreu), Suiza (Patricia Rodríguez-Patrón) y la Unión Europea (Antonio López Castillo).

Torres Del Moral, Antonio, Constitucionalismo bistórico español, Servicio de Publicaciones de la Facultad de Derecho, Universidad Complutense, Madrid, 2009.

Trujillo Fernández, Gumersindo, «Principio federal y Estado autonómico». En J. Cano Bueso y A. Porras Nadales: Parlamento y consolidación democrática. Madrid, Parlamento de Andalucía/Tecnos, 1994.

Tudela Aranda, José. El fracasado éxito del Estado autonómico. Una historia española. Madrid, Marcial Pons, 2016.

Varela Suanzes-Carpegna, Joaquín, «Estudio Preliminar» a Constituciones y Leyes Fundamentales, Vol. I de la colección Leyes políticas españolas 1808-1978, dirigida por Joaquín Varela Suanzes-Carpegna. Madrid, Iustel, 2012. 
Varela Suanzes-Carpegna, Joaquín y Muñoz MaChado, Santiago, La organización territorial del Estado en España. Del fracaso de la I República a la crisis del Estado autonómico. Fundación Coloquio Jurídico Europeo, Madrid, 2013.

VV.AA, (Gregorio Cámara Villar, coord.) Por una reforma federal del Estado autonómico. Fundación «Alfonso Perales, 2012»: http://www.fundacionalfonsoperales.com/ wp-content/uploads/2012/12/Libro-Federalismo.pdf

VV.AA, Por una reforma constitucional federal, Documento de trabajo de la Fundació «Rafael Campalans», publicado en Papers de la Fundació, n. ${ }^{\circ}$ 164, Mayo de 2013 ( elaborado por Xavier Arbós, Meritchell Batet, Carme Chacón, Jaume Collboni, Miquel Iceta, Eduard Roig, Joaquín Tornos y Francesc Vallés. https:// reformafederal.files.wordpress.com/2013/05/164_papersdelafundacio.pdf.

VV.AA, [López Basaguren, Alberto y Escajedo San Epifanio, Leire (Editors)], The Ways of Federalism in Western Countries and the Horizons of Territorial Autonomy in Spain. 2 Vols. Berlin Heidelberg, Springer-Verlag, 2013.

VV.AA, (Teresa Freixes Sanjuán y Juan Carlos Gavara de Cara, Coordinadores), Repensar la Constitución. Ideas para una reforma de la Constitución de 1978; reforma y comunicación dialógica. Parte Primera. Madrid, Centro de Estudios Políticos y Constitucionales, 2016.

VV.AA, (Ángel J. Gómez Montoro, Ed.), La reforma del Estado Autonómico. Jornadas de Estudio sobre el Informe del Consejo de Estado. Madrid, Universidad de Navarra/ Centro de Estudios Políticos y Constitucionales, 2007.

VV.AA, (Coordinador: Enrique Álvarez Conde), El futuro del Estado autonómico. Madrid, Imap, Instituto Madrileño de Administración Pública/IDP, Instituto de Derecho Público, Universidad Rey Juan Carlos, 2007.

VV.AA, Reflexiones y propuestas sobre la reforma de la Constitución Española. Enrique Álvarez Conde (dir.), Manuel Álvarez Torres (ccord.). Granada, Comares, 2017.

VV.AA, (Vicente Garrido Mayol, Director), Modelo de Estado y reforma de los Estatutos. Cátedra de Derecho Autonómico, Fundación Profesor Manuel Broseta, Universitat de València, 2007.

VV.AA, (Miguel Ángel Aparicio, Director), La Descentralización y el Federalismo. Nuevos modelos de Autonomía Política (España. Bélgica, Canadá, Italia y el Reino Unido). Barcelona, Cedescs, Estudios Constitucionales y Políticos, 1999.

VV.AA, (Javier García Roca, Editor), Pautas para una reforma constitucional. Informe para el debate. Cizur Menor (Navarra), Thomson Reuters Aranzadi, 2014.

VV.AA, La cuestión catalana, Revista Teoría y Realidad Constitucional, número 37, primer semestre de 2016, monográfico.

VV.AA, ( José Tudela Aranda y Félix Knüpling, Eds.) España y modelos de federalismo. Centro de Estudios Políticos y Constitucionales/ Fundación Manuel Giménez Abad, de Estudios Parlamentarios y del Estado Autonómico, Madrid, 2010.

VV.AA, El Estatuto de Autonomía para Andalucía. Debates sobre el ayer, el hoy y el mañana (Coordinador, Carlos Alberto Chernichero Díaz). Sevilla, Instituto Andaluz de Administración Pública, 2001. 
VV.AA, Sistemas federales. Una comparación internacional. (Wilhem Hofmeister y José Tudela Aranda, eds.). Zaragoza, Konrad Adenauer Stiftung/ Fundación Manuel Giménez Abad de Estudios Parlamentarios y del Estado Autonómico, 2017.

Title:

The territorial organization of Spain. A reflection on the state of the question and keys to constitutional reform.

\section{Summary:}

1. Introduction. 2. The Republican Federal Constitution Project of 1873. 3. The Constitution of 1931 and the Second Republic. 4. The opening of the autonomous process with the Constitution of 1978. 5. The evolution of the Autonomous State. 6. Towards a constitutional reform? Some keys in federal sense. 7. Special reference to the Catalan question. BIBLIOGRAPHIC NOTE

\section{Resumen:}

En este trabajo se reflexiona con amplia perspectiva histórica sobre la cuestión de la organización territorial del Estado en España hasta desembocar en la situación actual y ofrecer, a la luz de esa evolución, algunas claves para la reforma constitucional en sentido federal que se entiende necesaria en nuestros días.

Partiendo de la evidencia de que la respuesta ofrecida por el constitucionalismo histórico español ante la forma territorial del Estado ha sido, como tónica general, la de configurar a España como un Estado unitario, centralizado, simbolizado por la Monarquía, se analizan sumariamente los dos grandes intentos de distinto signo que existieron antes de la Constitución de 1978 para salir del unitarismo y poner en pie modelos de descentralización política. La primera experiencia, de cuño federal, gestada durante la Primera República (1873-1874) se consumió en unos meses sin que pudiera discutirse siquiera el Proyecto de Constitución Federal de 1873, elaborado en el marco de una situación política y social extremadamente convulsa que desembocó en la anarquía del cantonalismo. La segunda, que durante el quinquenio de la Segunda República (1931-1936) ensayó la compatibilidad de un llamado «Estado integral» con la autonomía de las regiones, fue llevada muy parcialmente a la práctica y acabó con la sublevación militar encabezada por el general Franco y la guerra civil (1936-1939). 
Tras el franquismo y la Transición democrática, la Constitución de 1978 no constitucionalizó un modelo preciso y acabado de descentralización política sino que prefiguró un Estado «descentralizable», abierto a distintas posibilidades, dando curso a un «proceso autonómico» a partir del reconocimiento del derecho a la autonomía de las nacionalidades y regiones en su Título Preliminar y el establecimiento de complejas reglas en el Título VIII. La apertura de este proceso fue evolucionando hacia el llamado «Estado autonómico» mediante la práctica política y la doctrina del Tribunal Constitucional, desarrollándose paulatinamente con las técnicas del federalismo y en su campo de atracción hasta configurar un Estado federal en los hechos, aunque con notorias carencias e incoherencias de estructura y funcionamiento. El estado autonómico entró en crisis a partir, sobre todo, de los embates del nacionalismo político en el País Vasco a comienzos de la década de 2000 y especialmente en Cataluña desde mitad de la década pasada hasta la actualidad, momento álgido del desafío secesionista.

A lo largo del trabajo se intenta mostrar primero que si bien en 1873 , 1931 y 1978 hubo un rotundo rechazo del centralismo y una aspiración indubitada al establecimiento de la autonomía regional bajo distintas formas, no pudo fraguarse en ninguno de estos momentos, por diferentes razones, una neta voluntad constituyente en esta materia que estuviera en condiciones de sostener eficazmente un modelo definido. Se considera que por esta y otras causas la cuestión territorial sigue estando recurrentemente abierta en canal, a la espera de una constitucionalización adecuada que permita vertebrar con la estabilidad necesaria el Estado español. Tras un diagnóstico general del modelo autonómico en su evolución en la órbita del federalismo, se abordan, de acuerdo con este planteamiento, los elementos centrales que se consideran necesarios para una reforma constitucional en clave federal que racionalice un Estado que ya es federal en los hechos y que permita integrar todos los territorios con sus singularidades, dedicando una especial atención a la cuestión catalana en el marco del actual desafío independentista.

\begin{abstract}
:
In this work we reflect from a broad historical perspective on the question of the territorial organization of the State in Spain leading to the current situation and offer, in light of this evolution, some keys to the constitutional reform in a federal sense that is deemed necessary in our days.

Starting from the evidence that the answer offered by the Spanish historical constitutionalism to the territorial shape of the State has been, in general, to configure Spain as a unitary, centralized state, symbolized by the Monarchy, we analyzed the two large and different attempts that existed prior to the 1978 Constitution to emerge from unitarianism and to establish models of political decentralization. The first experience, with a federal character, developed during the First Republic (1873-1874) was consumed in a few months without even being able to discuss the Draft of the Federal Constitution of 1873 , elaborated in the context of an extre-
\end{abstract}


mely convulsive political and social situation that ended in the anarchy of cantonalism. The second, which during the five-year period of the Second Republic (1931-1936) tested the compatibility of a so-called «integral state» with the autonomy of the regions, was taken very partially into practice and ended with the military uprising led by general Franco and the Civil War (1936-1939).

After Franco's regime and the democratic Transition, the Constitution of 1978 did not constitutionalize a precise model of political decentralization but prefigured a «decentralized» State, open to different possibilities, giving way to an «autonomic process» from the recognition of the right to the autonomy of nationalities and regions in their Preliminary Title and the establishment of complex rules in Title VIII. The opening of this process evolved towards the so-called «Autonomous State» through political practice and the doctrine of the Constitutional Court, developing gradually with the techniques of federalism and in its field of attraction until setting up a the facto federal State, although with notorious deficiencies and inconsistencies in structure and functioning. The autonomous state came into crisis starting, above all, from the clashes of political nationalism in the Basque Country in the early 2000s and especially in Catalonia from the middle of the last decade to the present, the height of the secessionist challenge.

In the course of this work we try to show that, although in 1873, 1931 and 1978 there was a resounding rejection of centralism and a clear aspiration to establish regional autonomy under different forms, it could not be forged in any of these moments, for different reasons, a net constituent will in this matter that would be able to effectively support a defined model. It is considered that for this and other causes the territorial question is still recurrently open in a channel, pending the appropriate constitutionalization that allows to vertebrate with the necessary stability the Spanish State. Following a general diagnosis of the autonomous model in its evolution in the orbit of federalism, the central elements are considered according to this approach, which are are regarded as necessary for a constitutional reform in a federal key that rationalizes a State that is already federal in the facts and that allows to integrate all the territories with their singularities, devoting a special attention to the Catalan question within the framework of the present independence challenge.

\section{Palabras clave:}

Organización territorial del Estado; Estado autonómico; Estado federal; Reforma constitucional; Reforma federal; Federalismo; España; Cataluña

\section{Key words:}

Territorial organization of the State; Autonomous state; Federal state; Constitutional reform; Federal reform; Federalism 